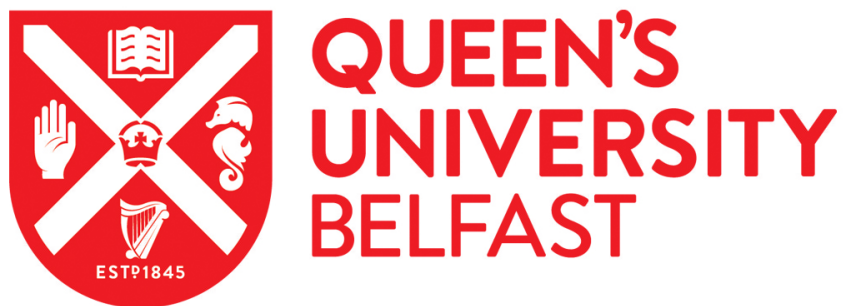

\section{The Challenges Faced in Developing Novel Drug Radiation Combinations in Non-small Cell Lung Cancer}

Harrow, S., Hanna, G., Faivre-Finn, C., McDonald, F., \& Chalmers, A. J. (2016). The Challenges Faced in Developing Novel Drug Radiation Combinations in Non-small Cell Lung Cancer. Clinical oncology (Royal College of Radiologists (Great Britain)), 28(11), 720-725. https://doi.org/10.1016/j.clon.2016.08.004

Published in:

Clinical oncology (Royal College of Radiologists (Great Britain))

Document Version:

Peer reviewed version

Queen's University Belfast - Research Portal:

Link to publication record in Queen's University Belfast Research Portal

\section{Publisher rights}

Copyright 2016 Elsevier

This is an open access article published under a Creative Commons Attribution-NonCommercial-NoDerivs License

(https://creativecommons.org/licenses/by-nc-nd/4.0/), which permits distribution and reproduction for non-commercial purposes, provided the author and source are cited.

\section{General rights}

Copyright for the publications made accessible via the Queen's University Belfast Research Portal is retained by the author(s) and / or other copyright owners and it is a condition of accessing these publications that users recognise and abide by the legal requirements associated with these rights.

Take down policy

The Research Portal is Queen's institutional repository that provides access to Queen's research output. Every effort has been made to ensure that content in the Research Portal does not infringe any person's rights, or applicable UK laws. If you discover content in the Research Portal that you believe breaches copyright or violates any law, please contact openaccess@qub.ac.uk. 


\section{The challenges faced in developing novel drug radiation combinations in non-small cell lung cancer}

\section{Introduction.}

In 2012 there were more than 40,000 new cases of lung cancer in the UK [1]. In the treatment of this disease radiotherapy is a central treatment modality [2]. In spite of significant technical developments in the radiotherapy, local recurrence rates following curative intent radiotherapy in the treatment of non-small cell lung cancer (NSCLC) remain high [3]. Radiation dose escalation is one potential avenue of optimisation, but is limited by adjacent normal tissue tolerances [4]. Another strategy to optimise the biological effectiveness of radiotherapy is by co-administration of therapeutic agents that preferentially sensitize malignant cells to radiotherapy. Combining cytotoxic chemotherapy with radiotherapy is such a strategy and has been shown to improve both local control rates and overall survival $[5,6]$. However, the therapeutic gain achieved by adding cytotoxic chemotherapy to radiotherapy is modest $(4.5 \%$ gain in overall survival at 5 years with concurrent versus sequential chemotherapy) and is associated with increased toxicity [6]. With increasing understanding of the molecular mechanisms underlying radioresistance and the emergence of systemic agents that can target these mechanisms there is growing interest in considering what additional benefit these agents may add to radiotherapy and how to combine the two modalities in the most effective manner.

This strategy of optimising radiotherapy with systemic therapy is principally aimed at those patients whose disease is localised and potentially curable. However radiotherapy is also used for palliation of local symptoms in patients with advanced or metastatic disease [7]. In this patient group, investigators are starting to evaluate how radiotherapy may be used to optimise the efficacy of systemic therapies such the immune modulating agents. This concept in considered in more detail in another paper in this special edition [8]. 
In this article we consider aspects of tumour biology and radioresistance which can be exploited by novel agents delivered in combination with radiotherapy, and the important issues to be considered when combining novel agents with radiotherapy in clinical studies. To illustrate these issues and present potential solutions, we report on the consensus reached at a National Cancer Research Institute (NCRI) Clinical Translational Radiotherapy Research Working Group (CTRad) workshop, held in Glasgow in February 2016, and the resulting plans to develop two umbrella study platforms to successfully test and implement such novel radiotherapy combinations.

\section{Current systemic therapy combinations with radiotherapy in the management of NSCLC.}

At present, concurrent systemic therapy has no established role in combination with radiotherapy in the curative treatment of stage I or II NSCLC. However, approximately one third of patients when diagnosed with NSCLC have locally advanced, stage IIIA or IIIB disease, for whom curative surgical treatment is not an option [9]. Those patients who have a good performance status and acceptable lung function can usually be treated with curative intent radiotherapy, and the addition of chemotherapy has been shown to improve outcomes in this population [10]. Radiotherapy as a single agent may be offered to patients whose fitness or comorbidities preclude the use of chemotherapy either as induction treatment or concurrent with radiotherapy. In the last decade there has been a shift to using platinum chemotherapy concurrently with high dose radiation, based on data showing better outcomes when compared with induction chemotherapy [6]. However, this approach is suitable for less than half of patients with locally advanced NSCLC [11,12].

Concurrent chemo-radiotherapy is associated with an improvement in survival [6]. Although some discrepancies in practice exist, the preferred chemotherapy regimen is usually based on a platinumcontaining doublet [2]. The optimum radiotherapy dose and fractionation to combine with systemic treatment is less clear. Currently most reported regimens deliver 2 Gy per fraction, 5 days per week, to a total dose of 60-66Gy. 
This issue has been the subject of a number of clinical trials. Most recently the results of the RTOG 0617 study were reported, in which patients were randomised to 60Gy in 6 weeks versus 74Gy in 7.5 weeks and, in a $2 \times 2$ design, were also randomised to the addition or not of cetuximab to concurrent platinum based chemotherapy [13]. Patients in the $74 \mathrm{~Gy}$ arm had poorer survival than those in the lower dose arm (20.3 months versus 28.7 months). The addition of cetuximab for all comers in this cohort did not improve survival, which has been a disappointing finding, given encouraging prior results from the SCATCH pilot study [14]. The outcomes of this trial have undermined the validity of dose escalation alone, using conventional fractionation, as a method to improve local control or survival in NSCLC [15].

Another approach to improving outcomes for patients with locally advanced NSCLC is to alter radiotherapy fractionation, either by increasing the number of fractions delivered each day, delivering the radiation over a shorter period of time (acceleration), or a combination of the two $[4,16]$. Conversely, achieving acceleration by increasing the radiation dose per fraction (hypofractionation) in stage III NSCLC has also been investigated and in the SOCCAR phase II randomised trial, 55Gy in 20 fractions over four weeks was evaluated in combination with cisplatin and vinorelbine chemotherapy delivered either concomitantly or sequentially [17]. In this study the median survival was 24.3 months in the concurrent setting compared to 18.4 months in the sequential arm and there has been much interest and progress in combining other modified fractionation regimens with cytotoxic chemotherapy $[18,19]$

\section{Potential therapeutic targets to enhance radiotherapy effectiveness.}

In describing the revised hallmarks of cancer, Hanahan and Weinberg provide a useful framework within which to consider mechanisms through which to increase the tumoricidal effects of radiation [20]. Many of these approaches have mechanistic potential to enhance radiation induced lethal 
damage within the tumour cell and are presented in table 1 [21-28]. It should be noted that a number of studies examining the combination of novel or targeted agents with radiotherapy in NSCLC are underway [29].

Table 1: Hallmarks of cancer and potential mechanisms to enhance effect of radiotherapy (adapted from Hanahan and Weinberg [17]).

\begin{tabular}{|c|c|c|}
\hline Hallmark of Cancer & $\begin{array}{l}\text { Potential mechanism for } \\
\text { enhancement of radiation effect }\end{array}$ & $\begin{array}{l}\text { Therapeutic agents for } \\
\text { consideration }\end{array}$ \\
\hline Genomic instability and mutation & $\begin{array}{l}\text { Radiation induced DNA damage is } \\
\text { augmented by inhibition of DNA } \\
\text { damage repair processes }\end{array}$ & $\begin{array}{l}\text { PARP inhibition, ATM inhibition, } \\
\text { ATR inhibition and Wee1-kinase } \\
\text { inhibition [21] }\end{array}$ \\
\hline Tumour promoting inflammation & $\begin{array}{l}\text { Paracrine cell signalling which } \\
\text { switches on survival pathways is } \\
\text { blocked leading to reduced cell } \\
\text { survival }\end{array}$ & CXCR2 inhibition [22] \\
\hline Enabling replicative immortality & $\begin{array}{l}\text { Malignant cell ability to cope with } \\
\text { telomere damage from } \\
\text { radiotherapy is reduced }\end{array}$ & Telomerase inhibitors [23] \\
\hline Avoiding immune destruction & $\begin{array}{l}\text { Radiation induced inflammation } \\
\text { within the tumour is detected by } \\
\text { activated T-cells which in turn } \\
\text { leads to anti-tumour adaptive } \\
\text { immune response }\end{array}$ & $\begin{array}{l}\text { Immune modulating agents (e.g. } \\
\text { CTLA4, PD-1, PD-L1 checkpoint } \\
\text { inhibitors) [24] }\end{array}$ \\
\hline Resisting Cell Death & $\begin{array}{l}\text { Therapeutic agent overcomes } \\
\text { tumour cell ability to avoid } \\
\text { apoptosis following radiotherapy }\end{array}$ & $\begin{array}{l}\text { BH3 mimetics, cFLIP inhibition } \\
\text { [25] }\end{array}$ \\
\hline
\end{tabular}




\begin{tabular}{|l|c|c|}
\hline Evading Growth Suppressors & $\begin{array}{r}\text { Proliferative potential after } \\
\text { exposure to radiation is reduced } \\
\text { or terminated }\end{array}$ & Inhibitors [26] \\
\hline Sustaining Proliferative Signalling & $\begin{array}{c}\text { Following radiation the tumour } \\
\text { cell proliferative signalling } \\
\text { response is reduced which }\end{array}$ & \\
& triggers apoptosis & \\
\hline Deregulating Cellular Energetics & AKT-mediated enhanced aerobic & Aerobic Glycolysis inhibitors [28] \\
& glycolysis radioresistance within & \\
& tumour cells is reduced & \\
\hline
\end{tabular}

\section{Challenges when designing clinical studies evaluating novel agent/radiotherapy combinations.}

Central to the premise of more targeted therapy is an understanding of the molecular characteristics of each patient's tumour. Molecular sub-typing has transformed treatment pathways for the systemic management of advanced NSCLC [30] and it is likely that molecular subtyping will be essential in determining the appropriate systemic therapy agent to combine with radiotherapy for a given patient. Molecular sub-typing is currently reliant on tissue blocks rather than cytological sample, but many novel methods that seek to optimise molecular analysis are under development [31]. In general, molecular sub-typing requires biopsy samples that are representative of the tumour and of sufficient size to permit analysis. Given the impact that tumour biology is likely to have on novel drug and radiotherapy combinations, it is critical that clinical trials in this area include carefully considered, biologically relevant translational components. One challenge is the high degree of tumour heterogeneity that appears to characterise NSCLC in comparison to other primary tumour sites; the degree to which this will influence response to novel drug/radiotherapy combinations is not yet known but should certainly be borne in mind [32]. 
Innovative trial design will also be key to the success of future drug/radiotherapy combination studies in NSCLC [33]. One of the key dose limiting toxicities in these patients is pneumonitis, and the timings and severity of this side effect are variable and poorly understood. The majority of patients who will go on to develop late pneumonitis after radiotherapy have measurable signs or symptoms by 3 to 6 months after completion of radiotherapy [34]. In early phase trials of a novel combination, there is a competing interest between ensuring that any increases in late toxicity are detected and acted upon and the objective of completing the study in the shortest possible time. The concept of using predicted risks and Bayesian models to estimate anticipated toxicity at given time points can be using to accelerate trial recruitment in a safe and robust manner [35]. Of particular interest is the time-toevent continual reassessment method [36], a methodology that has been used in clinical trials of novel radiotherapy-drug combinations in other disease settings [37] and is increasingly viewed as the most appropriate study design in this research field.

Finally, with regard to trial design, the end-points by which clinical efficacy of the radiotherapy-drug combination are assessed need to be carefully considered. Pseudo-progression of the apparent disease in the irradiated field is a well-recognised clinical entity after both conventional chemoradiotherapy and stereotactic ablative body radiotherapy $[38,39]$. Any potential studies in this area will need have mechanisms to take pseudo-progression into account and may need to consider the more robust end-point of overall survival when assessing clinical efficacy. This and other relevant issues are covered in more detail in the Consensus Statement on clinical development of new drugradiotherapy combinations that was recently published in Nature Reviews Clinical Oncology [40]. 


\section{NRCI CTRad UK Consensus on radiotherapy-drug combination studies in NSCLC.}

Recognising both the opportunities and the challenges in this area, and the importance of an integrated, multidisciplinary approach, NCRI CTRad organised a two day workshop at the Beatson West of Scotland Cancer Centre, Glasgow, in February 2016. This was attended by clinical and medical oncologists specialising in the treatment of lung cancer, along with methodologists, statisticians, scientists and industry partners from across the UK. After a review of the current clinical trials portfolio it was agreed that there was both a requirement and an important opportunity to develop high quality clinical trials to evaluate novel drug-radiotherapy combinations. In addition it was considered that the NCRI Lung Clinical Studies Group should support the development and implementation of these studies.

One of key aims of the meeting was to decide which radiotherapy regimen should be used for any novel combinations with curative intent radiotherapy. After considerable discussion the group agreed that the radiotherapy backbone of any novel drug radiation combination study with curative intent should utilise a standard 2 Gy fractionation. The rationale behind this decision was that 2 Gy per fraction regimes are known to be relatively safe, are well documented and their radiobiology is very well characterised, in terms of both tumour and normal tissue effects. Although both hyperfractionated accelerated and hypofractionated radiotherapy schedules may be more effective that $2 \mathrm{~Gy}$ per daily fraction regimens, the attendees felt that altered fractionation regimes were less well characterised and might be associated with increased risks of additional toxicity when combined with novel agents. It was agreed that the phase 1 studies combining novel agents with radiotherapy should have toxicity measures as their primary end points and as such it was felt that the radiotherapy dose should not be escalated. Furthermore using 2 Gy per fraction would permit international comparison of results. Of course, testing of any novel agent with altered fractionation should be possible at a later stage. Discussion of the minimum technical requirements for planning and delivering radiotherapy to potential study patients led to the conclusions that all patients should have 
a 4DCT planning scan and their treatment should be delivered by IMRT with image guidance for treatment verification.

It became clear that there were essentially two patient populations in which further investigation was warranted, and that two scientific themes held the most potential. In patients with stage III disease there is an opportunity to investigate inhibitors of the DNA damage response (DDR) in combination with curative intent radiotherapy, while in patients with stage IV disease the combination of radiotherapy with immunomodulating agents is of most interest.

\section{Proposed study in stage III NSCLC}

It was agreed that the study of DDR inhibitors in combination with radical radiotherapy for stage III NSCLC should be a phase I study designed along the lines of the ongoing Lung MATRIX study in an umbrella type concept (see figure 1) [41]. The most suitable patients for this study will be those who are fit enough to undergo radical radiotherapy, with or without prior induction chemotherapy, however patients who are suitable for concurrent chemo-radiotherapy would not be included because of the established risk of exacerbating normal tissue toxicities when combining DDR inhibition with concomitant chemoradiation. In this population a performance status of 0 to 2 would be acceptable for inclusion, as long as PS2 is due to disease and not comorbidities. A radiotherapy treatment dose of 60-66 Gy in 30-33 fractions was recommended, with the total dose determined by key 'organ at risk' dose constraints according to the isotoxic dose escalation concept [42]. By standardising the dose delivered to the critical normal tissues, this approach would ensure that any additional normal tissue toxicity detected would reflect the impact of the novel drug rather than discrepancies in radiotherapy dose. 


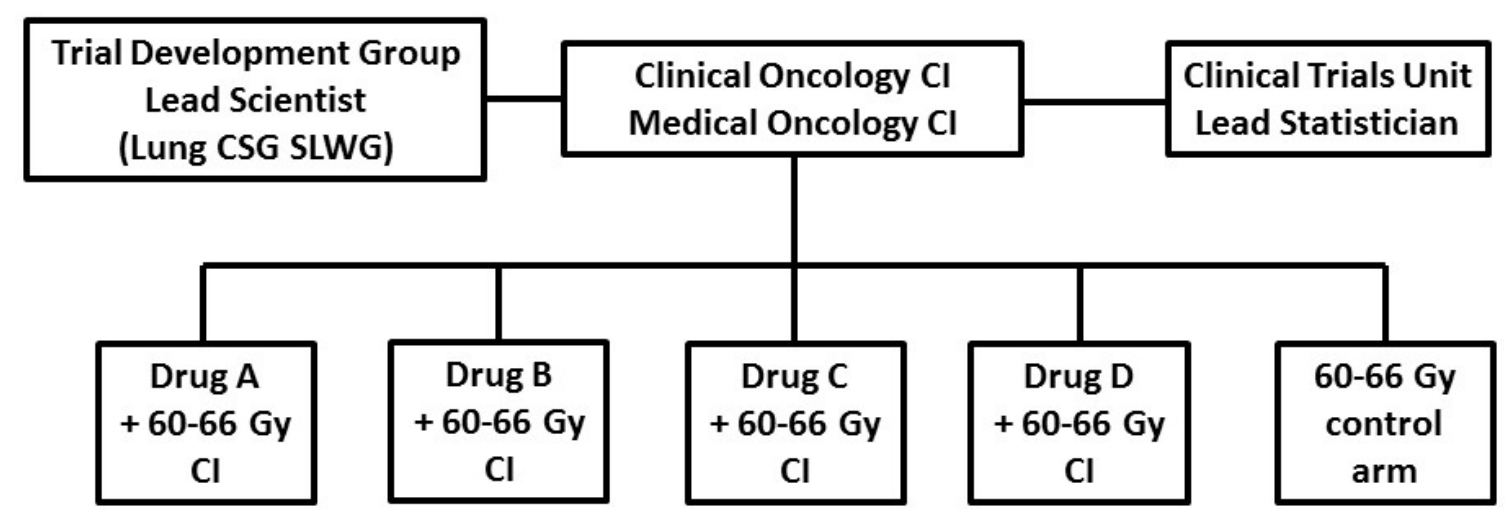

Figure 1: Outline of a the planned phase I multi-arm drug dose escalation study of molecularly targeted agents in combination with radical radiotherapy for patients with stage III NSCLC

A standard phase 1 trial design will not be optimal to permit patient accrual in any novel agent and radiotherapy study design. Furthermore, given the competing morbidities that patients with lung cancer face, there is the potential to over- or under-estimate important toxicities form the novel combination, thus novel trial design is imperative [43]. This phase I drug dose escalation study will use a TITE-CRM or similar Bayesian design to maximise accuracy and value of all relevant toxicity data, including acute, subacute and late effects. The primary outcome measure for each arm will be the recommended phase II dose of each drug to take forward. It was agreed that a comparative arm including patients with similar characteristics and treated with the same dose fractionation will facilitate the causality assessment for adverse drug-radiotherapy event. Initially, the umbrella study 
will consider drugs from the AstraZeneca DDR inhibitor portfolio, given the favourable potential mechanism of synergy and promising results from other tumour sites (e.g. PARP inhibitor, Wee1 Kinase inhibitor, ATR inhibitor, ATM inhibitor) [21]. Additional drugs may be added after the study is successfully initiated. The study will also incorporate 'proof of mechanism' biomarkers where possible which have the mechanistic potential to assess the status of key DDR genes which may be critical in response to both the DDR agents and to radiotherapy (e.g. the Almac Diagnostics ${ }^{\circledR}$ DNA Damage Repair Deficiency assay - DDRD) [44]. If future biomarkers become available that have the potential to enrich any of the relevant arm(s) of the study, these will be incorporated in an adaptive design. It was recommended that the study should use a centralised pharmacy.

\section{Proposed study in stage IV NSCLC}

The design of this study proved to be particularly challenging. A phase II multi-arm study of immunomodulatory agents in combination with radiotherapy was considered to be an attractive study for patients with stage IV NSCLC. Stage III NSCLC patients who are unsuitable for treatment with curative intent might form an additional cohort. It was agreed that patients should have received standard first line systemic therapy prior to enrolment. This would be followed by a stratification based on the indication for palliative radiotherapy as shown in figure 2. Three possible radiotherapy strategies were identified: standard palliative radiotherapy (20 Gy in 5 fractions) to sites of metastatic disease, stereotactic ablative radiotherapy to sites of metastatic disease and higher dose palliative radiotherapy (36 Gy in 12 fractions) to the primary site. In terms of the immunomodulatory drugs being considered there is a growing body of phase I radiotherapy combination data for several agents including key candidates such as the immune checkpoint modulators including inhibitors of the programmed death receptor and its ligand 1 (PD-1 and PD-L1) [20]. It is likely that a variety of different drugs will be included in the various arms. 


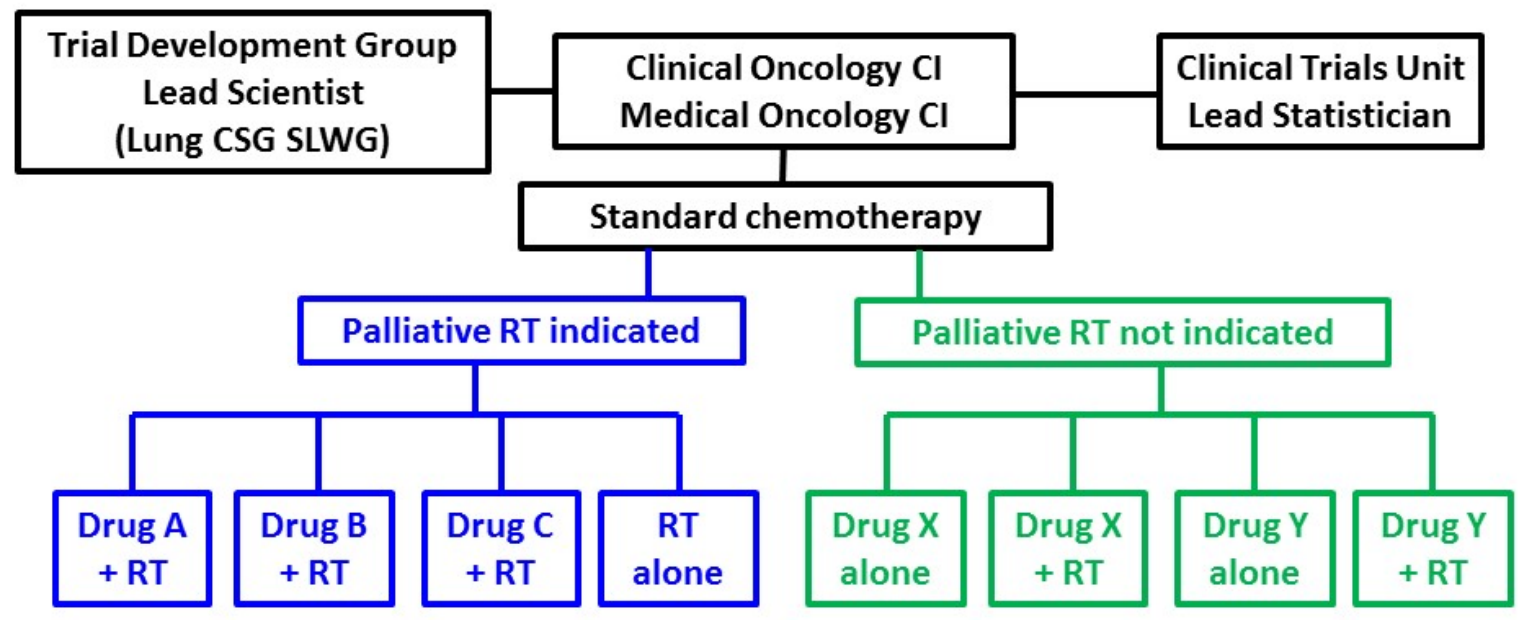

Figure 2: Outline of the planned phase II multi-arm study of immunomodulatory agents in combination with radiotherapy for patients with stage IV NSCLC

\section{Conclusions}

During the meeting there was a national enthusiasm for evaluating novel radiotherapy-drug combinations in NSCLC. The UK lung cancer clinical community has agreed a consensus on how to accelerate the clinical development of novel agents in combination with radiotherapy in this cancer of unmet need. Key issues that had previously been contentious were discussed, such as the most suitable radiotherapy dose for the radical setting, and agreement reached on how best to proceed. A multicentre, multidisciplinary consortium of researchers has begun the task of designing and assembling the necessary trial infrastructure and our aim is to fund and open the suggested studies within the next two years. 


\section{Acknowledgements:}

\section{We wish to acknowledgement the meeting attendees:}

Dr. Andrew Bates - University Hospital Southampton;

Dr. Neeraj Bhalla - Clatterbridge Cancer Centre;

Louise Brown - MRC Clinical Trials Unit University College London;

Dr. Sarah Brown - Leeds Institute of Clinical Trials Research;

Caroline Kelly - Institute of Cancer Sciences, University of Glasgow;

Dr. Carolyn Chan - NCRI CTRad;

Dr. Kevin Franks - St James's Institute of Oncology, Leeds Cancer Centre;

Dr.Sonja Gill - AstraZeneca;

Dr. Alastair Greystoke - Northern Centre for Cancer Care, The Newcastle upon Tyne Hospitals;

Dr.Susan Harden - Cambridge Cancer Centre;

Dr. Matthew Hatton - Sheffield Teaching Hospital;

Dr. Geoff Higgins - Department of Oncology, University of Oxford;

Dr. David Landau - Guys and St Thomas' NHS foundation Trust;

Dr. Jason Lester - Velindre Cancer Centre, Cardiff;

Dr. Nazia Mohammed - Beatson West of Scotland Cancer Centre;

Dr. Mark O'Connor - AstraZeneca;

Dr. Noelle O'Rourke - Beatson West of Scotland Cancer Centre;

Dr. Pieter Postmus - Clatterbridge Cancer Centre;

Dr. Paul Shaw - Velindre Cancer Centre, Cardiff.

NCRI CTRad wishes to acknowledge its funding partners:

Cancer Research UK;

Medical Research Council;

Chief Scientist Office, Scotland; 
Health and Care Research, Wales;

Research and Development Office, Public Health Agency, Northern Ireland;

Department of Health, England.

More information regarding NCRI CTRad is available at: http://ctrad.ncri.org.uk/ 


\section{References:}

1.) Cancer Research UK - Lung cancer statistics. Available at:http://www.cancerresearchuk.org/healthprofessional/cancer-statistics/statistics-by-cancer-type/lung-cancer. [Accessed on 26th May 2016].

2.) National Institute for Health and Care Excellence. The diagnosis and treatment of lung cancer (update). Clinical Guidance. Cardiff: National Collaborating Centre for Cancer; 2011. Report No.: 24.

3.) McCloskey P, Balduyck B, Van Schil PE, Faivre-Finn C, O'Brien M. Radical treatment of non-small cell lung cancer during the last 5 years. Eur J Cancer.2013 May;49(7):1555-64.

4.) Haslett K, Franks K, Hanna GG, Harden S, Hatton M, Harrow S, et al. Protocol for the isotoxic intensity modulated radiotherapy (IMRT)in stage III non-small cell lung cancer (NSCLC): a feasibility study. BMJ Open.2016 Apr 15;6(4):e010457.

5.) Pignon JP, Stewart LA. Randomized trials of radiotherapy alone versus combined chemotherapy and radiotherapy in stages IIIa and IIIb nonsmall cell lung cancer: a meta-analysis. Cancer. 1996 Jun $1 ; 77(11): 2413-4$

6.) Aupérin A, Le Péchoux C, Rolland E, Curran WJ, Furuse K, Fournel P, et al. Meta-analysis of concomitant versus sequential radiochemotherapy in locally advanced non-small-cell lung cancer. JClin Oncol. 2010 May 1;28(13):2181-90.

7.) Erridge SC, Gaze MN, Price A, Kelly CG, Kerr GR, Cull A, et al. Symptom control and quality of life in people with lung cancer: a randomised trial of two palliative radiotherapy fractionation schedules. Clin Oncol (R Coll Radiol). 2005 Feb;17(1):61-7.

8.) Hanna GG and Illidge T. Radiotherapy and immunotherapy combinations in NSCLC: a promising future? Clin Oncol (R Coll Radiol). 2016 Provisionally Accepted.

9.) Sacco P, Mainone P, Rossi A, Bareschino M, Schettino C, Guida C, et al. Combination of radiotherapy and targeted therapies in the treatment of locally advanced non-small cell lung cancer. TargOncol(2011) 6:171-180.

10.) Marino P, Preatoni A, Cantoni A. Randomized trials of radiotherapy alone versus combined chemotherapy and radiotherapy in stages IIla and IIlb nonsmall cell lung cancer. A meta-analysis. Cancer. 1995 Aug 15;76(4):593-601.

11.) De Ruysscher $D$, Botterweck A, Dirx M, Pijls-Johannesma $M$, Wanders $R$, Hochsenbag $M$, et al. Eligibility for concurrent chemotherapy and radiotherapy of locally advanced lung cancer patients: a prospective, population-based study. Ann Oncol 2009;20:98-102

12.) Helbrow J, MacNicoll F, Bayman N, Faivre-Finn C. Concurrent chemoradiotherapy for locally advanced, unresectable non-small cell lung cancer: a UK survey of current practice. ClinOncol (R CollRadiol) 2012;24(8):e127

13.) Bradley JD, Paulus R, Komaki R, Masters G, Blumenschein G, Schild S, et al. Standard-dose versus high-dose conformal radiotherapy with concurrent and consolidation carboplatin plus paclitaxel with 
or without cetuximab for patients with stage IIIA or IIIB non-small-cell lung cancer (RTOG 0617): a randomised, two-by-two factorial phase 3 study. Lancet Oncol. 2015 Feb;16(2):187-99.

14.) Hughes S, Liong J, Miah A, Ahmad S, Leslie M, Harper P, et al. A brief report on the safety study of induction chemotherapy followed by synchronous radiotherapy and cetuximab in stage III non-small cell lung cancer (NSCLC): SCRATCH study. J Thorac Oncol. 2008 Jun;3(6):648-51.

15.) Faivre-Finn C. Dose escalation in lung cancer: have we gone full circle? Lancet Oncol. 2015 Feb;16(2):125-7.

16.) Saunders MI, Rojas AM, Parmar MK, Dische S; CHART Trial Collaborators. Mature results of a randomized trial of accelerated hyperfractionated versus conventional radiotherapy in head-and-neck cancer. Int J Radiat Oncol Biol Phys. 2010 May 1;77(1):3-8.

17.) Maguire J, Khan I, McMenemin R, O'Rourke N, McNee S, Kelly V, et al. SOCCAR: A randomised phase II trial comparing sequential versus concurrentchemotherapy and radical hypofractionated radiotherapy in patients withinoperable stage III Non-Small Cell Lung Cancer and good performance status. Eur J Cancer. 2014 Nov;50(17):2939-49.

18.) Hatton MQ, Martin JE. Continuous hyperfractionated accelerated radiotherapy (CHART) and nonconventionally fractionated radiotherapy in the treatment of non-small cell lung cancer: a review and consideration of future directions. Clin Oncol (R Coll Radiol). 2010 Jun;22(5):356-64.

19.) Landau DB, Hughes L, Baker A, Bates AT, Bayne MC, Counsell N, et al. IDEAL-CRT: A Phase 1/2 Trial of Isotoxic Dose-Escalated Radiation Therapy and Concurrent Chemotherapy in Patients With Stage II/III Non-Small Cell Lung Cancer. Int J Radiat Oncol Biol Phys. 2016 Mar 28. pii: S0360-3016(16)003436 doi: 10.1016/j.ijrobp.2016.03.031. [Epub ahead of print].

20.) Hanahan D, Weinberg RA. Hallmarks of cancer: the next generation. Cell. 2011Mar 4;144(5):64674.

21.) Chalmers AJ. Science in Focus: Combining Radiotherapy with Inhibitors of theDNA Damage Response. Clin Oncol (R Coll Radiol). 2016 May;28(5):279-82.

22.) Rentoft $M$, Coates PJ, Loljung L, Wilms $T$, Laurell $G$, Nylander K. Expression of CXCL10 is associated with response to radiotherapy and overall survival in squamous cell carcinoma of the tongue. Tumour Biol. 2014 May;35(5):4191-8.

23.) Ferrandon S, Malleval C, El Hamdani B, Battiston-Montagne $P$, Bolbos R, Langlois JB, et al. Telomerase inhibition improves tumor response to radiotherapy in a murine orthotopic model of human glioblastoma. Mol Cancer. 2015 Jul 17;14:134.

24.) Hanna GG, Coyle VM, Prise KM. Immune modulation in advanced radiotherapies: Targeting outof-field effects. Cancer Lett. 2015 Nov 28;368(2):246-51.

25.) Thomas S, Quinn BA, Das SK, Dash R, Emdad L, Dasgupta S, et al. Targeting the Bcl-2 family for cancer therapy. Expert Opin Ther Targets. 2013 Jan;17(1):61-75. 
26.) Korinkova G, Cwiertka K, Paprskarova M, Dzubak P, Hajduch M. The radiosensitising effect of olomoucine derived synthetic cyclin-dependent kinase inhibitors. Neoplasma. 2010;57(2):161-9.

27.) Higgins GS, Krause M, McKenna WG, Baumann M. Personalized Radiation Oncology: Epidermal Growth Factor Receptor and Other Receptor Tyrosine Kinase Inhibitors. Recent Results Cancer Res. 2016;198:107-22.

28.) Shimura $T$, Noma $N$, Sano $Y$, Ochiai $Y$, Oikawa $T$, Fukumoto $M$, Kunugita N. AKT-mediated enhanced aerobic glycolysis causes acquired radioresistance by human tumor cells. Radiother Oncol. 2014 Aug;112(2):302-7.

29.) Koh PK, Faivre-Finn C, Blackhall FH, De Ruysscher D. Targeted agents in non-small cell lung cancer (NSCLC): clinical developments and rationale for the combination with thoracic radiotherapy. Cancer Treat Rev. 2012 Oct;38(6):626-40.

30.) Swanton C, Govindan R. Clinical Implications of Genomic Discoveries in LungCancer. N Engl J Med. 2016 May 12;374(19):1864-73.

31.) Hamilton PW, Wang $\mathrm{Y}$, Boyd $C$, James JA, Loughrey MB, Hougton JP, et al. Automated tumor analysis for molecular profiling in lung cancer. Oncotarget. 2015 Sep 29;6(29):27938-52.

32.) McGranahan N, Swanton $\mathrm{C}$. Biological and therapeutic impact of intratumor heterogeneity in cancer evolution. Cancer Cell. 2015 Jan 12;27(1):15-26.

33.) Harrington KJ, Billingham LJ, Brunner TB, Burnet NG, Chan CS, Hoskin P, et al. Guidelines for preclinical and early phase clinical assessment of novel radiosensitisers. Br J Cancer. 2011 Aug 23;105(5):628-39.

34.) Werner-Wasik M, Paulus R, Curran WJ Jr, Byhardt R. Acute esophagitis and late lung toxicity in concurrent chemoradiotherapy trials in patients with locally advanced non-small-cell lung cancer: analysis of the radiation therapy oncology group (RTOG) database. Clin Lung Cancer. 2011Jul;12(4):245-51.

35.) Bekele BN, Ji Y, Shen Y, Thall PF. Monitoring late-onset toxicities in phase I trials using predicted risks. Biostatistics. $2008 \mathrm{Jul} ; 9(3): 442-57$.

36.) Wages NA, Conaway MR, O'Quigley J. Using the time-to-event continual reassessment method in the presence of partial orders. Stat Med. 2013 Jan15;32(1):131-41.

37.)Kim MM, Parmar H, Cao Y, Pramanik P, Schipper M, Hayman J, et al. Whole Brain Radiotherapy and RRx-001: Two Partial Responses in Radioresistant Melanoma Brain Metastases from a Phase I/II Clinical Trial: ATITE-CRM Phase I/II Clinical Trial. TransIOncol. 2016 Apr;9(2):108-13.

38.) Ichihara E, Kiura K, Takigawa N, Omori M, Aoe M, Tanimoto M, Date H. Pseudoprogression of lung cancer after concomitant chemoradiotherapy. Jpn J ClinOncol. 2008 Feb;38(2):140-2.

39.) Frechette KM, Brown LC, Aubry MC, Wigle DA, Olivier KR. Pseudoprogression after stereotactic body radiotherapy. J ThoracOncol. 2014 Apr;9(4):e29-30. 
40.) Sharma RA, Plummer R, Stock JK, Greenhalgh TA, Ataman O, Kelly S, et al. Clinical development of new drug-radiotherapy combinations. Nat Rev Clin Oncol. 2016 Jun 1. doi: 10.1038/nrclinonc.2016.79. [Epub ahead of print]

41.) National Lung Matrix Trial: Multi-drug Phase II Trial in Non-Small Cell Lung Cancer. Available at: https://clinicaltrials.gov/ct2/show/NCT02664935 [Accessed on 26 th June 2016]

42.) Dingemans AM, Bootsma G, van Baardwijk A, Reymen B, Wanders R, Brans B, et al. phase I study of concurrent individualized, isotoxic accelerated radiotherapy and cisplatin-vinorelbine-cetuximab in patients with stage III non-small-cell lung cancer. J Thorac Oncol. 2014 May;9(5):710-6.

43.) Faivre-Finn C, Snee M. Traditional phase 1 and 2 studies in thoracic radiation oncology should be abandoned. Int J Radiat Oncol Biol Phys. 2014 Nov 1;90(3):487-9.

44.) Mulligan JM, Hill LA, Deharo S, Irwin G, Boyle D, Keating KE, et al. Identification and validation of an anthracycline/cyclophosphamide-based chemotherapy response assay in breast cancer. J Natl Cancer Inst. 2014 Jan;106(1):djt335. 